\title{
VARIAÇÃO ESTÁVEL OU MUDANÇA EM PROGRESSO? A EXPRESSÃO DO MODO SUBJUNTIVO EM TRÊS VARIEDADES DO PORTUGUÊS BRASILEIRO
}

Tatiana Schwochow Pimpão (FURG)

Wendel Silva dos Santos (UFMA)

Resumo: Tendo como referência a Teoria da Variação e Mudança (LABOV, 2001; [1972]2008), este trabalho tem o objetivo de promover uma discussão mais detalhada acerca da relevância da variável social faixa etária na compreensão da variação entre o modo subjuntivo e o modo indicativo em dados do português brasileiro. A reflexão empreendida parte da análise de resultados percentuais referentes a dados extraídos de entrevistas conduzidas com informantes de três capitais brasileiras: Florianópolis, São Paulo e São Luís. Pretende-se responder ao seguinte questionamento: a interpretação dos resultados aponta para um fenômeno de variação estável ou de mudança em progresso? Resultados mais gerais indicam que, em Florianópolis, a variação é estável e, em São Paulo e em São Luís, já há indícios de mudança.

Palavras-chave: Variação; Subjuntivo; Faixa etária; Capitais brasileiras.

Abstract: Based on Variation and Change Theory (LABOV, 2001; [1972] 2008), the aim of this work is to promote a more detailed discussion about the relevance of social variable age in the comprehension of the variation between subjunctive mood and indicative mood in brazilian portuguese data. The purpose is to bring reflections on data analysis from interviews with informants from these three brazilian capitals: Florianópolis, São Paulo e São Luís. The propose is to answer the following question: the interpretation of the results indicates a stable variation or a change in progress? The results indicate that variable stable is found in Florianópolis, and, otherwise, change in progress is observed in São Paulo and in São Luís.

Keywords: Variation; Subjunctive; Age groups; Brazilian capitals. 


\section{INTRODUÇÃO}

Há muito se questiona a viabilidade de se analisar, pelo olhar teórico-metodológico da Sociolinguística Variacionista, variáveis linguísticas para além do nível fonológico ${ }^{1}$, a exemplo da variação entre formas indicativas e subjuntivas em contextos em que o previsto, senão prescrito, seria a forma do subjuntivo (BECHARA, 2006; CUNHA; CINTRA, 1985; MENDES DE ALMEIDA, 2005), como em eu queria que ele fosse/era meu amigo, eu tenho medo de que ela vá/vai embora e se fosse/era necessário, eu faria a comida dela. Assim, analisar categorias modo-temporais, como a que se propõe aqui, configura-se como um importante desafio, já que é bastante complexa a atividade de definição dos contextos que funcionam, de fato, como variantes de uma variável, no sentido de Labov ([1972]2008).

Nesse sentido, o estudo da língua, a partir da variação, em sua perspectiva diacrônica, possibilita que se observe de que modo a mudança linguística estaria se implementando nas estruturas linguística e social de uma dada comunidade. O subjuntivo mostra vitalidade no português brasileiro, não em termos de prescrição gramatical, mas com o indicador de resultados de pesquisas sociolinguísticas. E, a despeito

1 Para uma ampla discussão sobre a análise de variáveis para além do nível fonológico, consultar o famoso debate entre Lavandera (1978) e Labov (1978). 
do que afirma Perini (2010), esse modo verbal não está desaparecendo. Diferentes estudos, especialmente os voltados para a pesquisa sociolinguística, têm apresentado evidências, respaldadas por resultados de dados de fala, da produtividade do subjuntivo em contextos linguísticos, com percentuais, em alguns casos, bastante altos. Esses trabalhos têm início na segunda metade do século XX, intensificamse na virada do século e continuam despertando interesse de muitos pesquisadores. Permitem um mapeamento da distribuição do uso variável do modo subjuntivo no território brasileiro, ainda que a concentração das pesquisas esteja nas regiões Sul, Sudeste e Nordeste.

É bastante relevante a contribuição dessas pesquisas, não somente por mapear diferentes estados, tempos verbais e contextos linguísticos, delineando uma significativa descrição do português brasileiro, como também por suscitar um importante questionamento, que justifica a proposta de discussão antecipada no título deste trabalho: a interpretação de resultados para três capitais brasileiras - Florianópolis, São Paulo, São Luís - aponta para um fenômeno de variação estável ou de mudança em progresso? O objetivo deste artigo consiste, portanto, em promover uma discussão mais detalhada acerca da relevância da variável social faixa etária na compreensão da variação entre o modo subjuntivo e o modo indicativo. 
Para responder a questionamentos dessa ordem, o controle da faixa etária dos falantes, enquanto variável social, tem sido a maneira que os estudos variacionistas encontraram para apresentar generalizações acerca do processo de mudança. Não são poucos os trabalhos voltados para o uso variável do modo subjuntivo no Português Brasileiro (doravante PB). Dentre eles, destacam-se aqueles em que a variável faixa etária é controlada: Wherritt (1977), Costa (1990), Rocha (1997), Pimpão (1999), Alves Neta (2000), Meira (2006), Carvalho (2007), Fagundes (2007), Alves (2009), Almeida (2010), Barbosa (2011), Pimpão (2012) e Santos (2015). Porém, em nenhum deles - ainda que se considerem a dimensão do trabalho e o investimento de tempo - a questão da variação estável ou da mudança associada ao uso variável do subjuntivo é discutida com profundidade. Desse modo, com base nos pressupostos teórico-metodológicos da Sociolinguística Laboviana (LABOV, 2001; [1972]2008), propõe-se a análise da faixa etária de falantes paulistanos, ludovicenses e florianopolitanos quanto ao uso variável do subjuntivo e do indicativo, com base nas pesquisas empreendidas por Pimpão (2012) e Santos (2015).

Os resultados mostram que em Florianópolis não há diferenças significativas entre os mais jovens (15-24 anos), os informantes na faixa intermediária (25-50) e os mais idosos 
(acima de 50), no que concerne ao uso do presente do modo subjuntivo e presente do modo indicativo. Os achados para São Paulo e São Luís, por sua vez, mostram que, entre os paulistanos, os mais jovens tendem a favorecer o indicativo nos contextos de subordinadas substantivas e adjetivas, enquanto que os ludovicenses mais jovens favorecem a forma inovadora em contextos de adverbiais, adjetivas e substantivas.

O artigo está organizado em quatro partes. Na primeira, discutem-se as bases teóricas que sustentam a análise e discussão dos resultados; na segunda, está a metodologia, seguida da análise e discussão dos resultados. Seguem-se as considerações finais.

\section{BASES TEÓRICAS E JUSTIFICATIVA}

Conforme se afirmou anteriormente, o emprego do modo subjuntivo vem atraindo cada vez mais o interesse da linguística brasileira (BOTELHO PEREIRA, 1974; WHERRITT, 1977; PIMPÃO, 1999; 2012; SANTOS, 2005; FAGUNDES, 2007; SANTOS, 2015). No geral, o interesse comum entre essas pesquisas está no objetivo de verificar se há casos em que o modo subjuntivo pode ser expresso ainda que se empreguem formas verbais do indicativo. De fato, o [subjuntivo] funciona como "estereótipo" (LABOV, [1972]2008), e o 
seu uso é comumente associado a noções de formalidade, escolarização e cuidado com a língua (WHERRITT, 1977), enquanto que usar o indicativo, em condições em que são previstas as formas do subjuntivo, está associado a noções de erro, informalidade e falta de escolarização. Pimpão (2012) e Santos (2015), no entanto, mostram que o indicativo é bastante produtivo na fala de 44 florianopolitanos, 36 paulistanos e 36 ludovicenses, com frequências de usos de 42\%, 39\% e 30\%, respectivamente. Análises minuciosas, realizadas por esses autores, mostraram, à semelhança de outros estudos, que a variação entre essas formas verbais é complexa, e que se dá motivada pela restrição de fatores linguísticos e sociais. Ademais, os percentuais de subjuntivo podem variar se considerado o conjunto de dados ou se considerados contextos linguísticos isolados, por exemplo, orações substantivas, orações adjetivas, orações adverbiais e orações com talvez.

Pimpão (2012) analisou casos, extraídos do Banco de Dados do Projeto VARSUL, em que a forma do presente do subjuntivo co-ocorre com a forma do presente do indicativo, na fala de 44 sujeitos nascidos em Florianópolis e de 24 nascidos em Lages. Com a consideração da cidade como uma variável independente, a autora contrasta dados de fala encontrados em 24 entrevistas de Florianópolis e em 24 de 
Lages, o que é denominado amostra 1. Em outra etapa da análise, com o controle de uma nova faixa etária (jovens) e de um novo nível de escolaridade (universitários), reúne 44 entrevistas de Florianópolis, a amostra 2. As análises reportadas aqui referem-se aos dados desta amostra. A autora também oferece uma análise diacrônica de dados extraídos de uma amostra composta por cartas ao redator publicadas em jornais locais (do século XIX até o fim do século $X X)$. Discute esses dados a partir de uma visão discursivo-pragmática, com base nos pressupostos teóricometodológicos da Sociolinguística Variacionista e dos pressupostos da Linguística Funcional (GIVÓN, 1995; 2001).

Os resultados apontam que o subjuntivo foi mais produtivo em Lages do que em Florianópolis (62\% e 54\%, respectivamente), e, nas análises dos dados da capital, observou-se que, entre os fatores linguísticos controlados, os que mostram relevância estatística são projeção temporal, pessoa, morfologia verbal, escolaridade e sexo. Para a amostra 2, o programa estatístico selecionou valores do submodo, morfologia verbal, sexo e escolaridade. Mesmo na amostra 2, que acrescenta entrevistas com jovens, a variável faixa etária não foi selecionada pelo programa estatístico. $\mathrm{Na}$ verdade, as primeiras variáveis selecionadas são de natureza discursivo-pragmática e morfológica, sendo as últimas 
de natureza social. Também as rodadas com os contextos linguísticos controlados isoladamente não apontaram a significância estatística da variável faixa etária.

Santos (2015), por sua vez, comparou a fala de paulistanos e ludovicenses, e analisou as formas do subjuntivo e do indicativo entre falantes dessas duas capitais. Para tal trabalho, o autor considerou as afirmações populares amplamente difundidas de que paulistanos não usam o subjuntivo (FREIRE, 2006), de um lado, e de que ludovicenses falam a melhor variedade do português brasileiro (HONÓRIO DO COUTO, 1986; TRAVAGLIA, 1996). O estudo focalizou a alternância de formas indicativas e subjuntivas em contextos nos quais ambas são possíveis: orações subordinadas adverbiais (é como se pra gente era/fosse normal), substantivas (eu sempre achava que ele ia/fosse dar bronca na gente) e relativas (não tem gente que anda/ande de Porsche na Freguesia do Ó).

O tempo verbal da subordinada mostrou-se como uma variável importante tanto para os dados ludovicenses quanto para os paulistanos (o presente favorece o emprego do indicativo); já o tipo de subordinador mostrou-se relevante apenas para os paulistanos (que tendem a empregar indicativo em orações condicionais com se, mas tendem a favorecer o subjuntivo nos demais casos). Para as orações 
substantivas, o verbo da oração principal foi selecionado como estatisticamente significativo para as duas amostras: verbos cognitivos favorecem formas do indicativo ("eu imagino que o médico vem pelas manhãs"). Entre paulistanos, também se verificou como relevante o tempo verbal da oração principal - o presente favorece o indicativo, enquanto passado e futuro favorecem o subjuntivo. Quando se trata de orações relativas, o tempo verbal da oração subordinada é relevante para os dados das duas capitais, com o presente favorecendo o indicativo.

Ao final do trabalho, o autor concluiu que os padrões de alternância de formas indicativas e subjuntivas não são tão diferentes em São Paulo e em São Luís, e que, ainda que o indicativo tenda a ser relativamente mais empregado em São Paulo, há indícios de mudança na direção do indicativo em São Luís, nas subordinadas adverbiais e substantivas. Numa análise global dos dados, em que cidade era uma variável dependente, Santos (2015) verificou que o indicativo é favorecido na fala paulistana - mas com um peso relativo pouco acima do ponto neutro (Peso Relativo .56), o que leva a pensar que tal diferença é pequena - considerandose as avaliações populares de que São Paulo não emprega subjuntivo e São Luís conserva o bom português.

De um modo geral, um dos interesses dessas pesquisas é verificar se o fenômeno de variação entre o subjuntivo 
e o indicativo configura um caso de variação estável ou se se trata de um processo de mudança em curso - em que a morfologia de subjuntivo estaria sendo progressivamente preterida em favor da morfologia de indicativo. Para tanto, este trabalho se vale essencialmente do construto teórico “tempo aparente" (LABOV, [1972]2008; 1978), a partir de amostras de dados de falas florianopolitana, paulistana e ludovicense estratificadas por sexo/gênero, faixa etária e escolaridade.

Além do interesse específico acerca da morfologia do subjuntivo, descrever e comparar o português falado em três cidades brasileiras pertencentes a regiões tão distintas, num país de extensões continentais, leva potencialmente a pelo menos duas outras contribuições. Por um lado, este trabalho tem um interesse empírico, ao contribuir para a descrição do português falado em três comunidades urbanas, o que pode levar a se identificar um padrão de uso das formas em foco. Por outro, tem um interesse teórico-metodológico, uma vez que poderá permitir um entendimento do conceito de comunidade de fala (GUY; ZILLES, 2007; LABOV, [1968]2006), bem como para fomentar a discussão acerca de métodos de coleta de dados de comunidades urbanas complexas e multifacetadas, e a maneira como se estabelece o processo de variação nessas comunidades, quanto ao uso do subjuntivo e 
do indicativo. De modo mais específico, interessa a discussão em torno do construto do tempo aparente (LABOV, 2001).

\section{VARIAÇÃO ESTÁVEL OU MUDANÇA LINGUÍSTICA}

Em 1968, a publicação de Weinreich, Labov e Herzog (doravante WLH) coloca em evidência a centralidade da variação e da mudança linguística. $\mathrm{Na}$ contramão da homogeneidade da língua, defendida pelos neogramáticos, pelo estruturalismo saussuriano e pelo formalismo gerativista, WLH lançam os fundamentos para uma teoria que assume a variação como inerente ao sistema e que se preocupa com os rumos e os problemas associados à mudança linguística.

$\mathrm{Na}$ introdução da obra, está nítida essa preocupação de relacionar a natureza da linguagem com a sociedade. A ideia do livro, de iniciativa de Weinreich, em 1966, e finalizada em 1967, pouco antes de sua morte, pretendia a defesa do rompimento entre estrutura e homogeneidade. Como explicar que as pessoas continuem falando enquanto a língua muda? Era preciso mostrar que a heterogeneidade da estrutura não é disfuncional e que, do aparente caos, é possível encontrar regularidades, padrões de uso. Os autores rompem, portanto, com a associação estruturalista entre homogeneidade e estrutura.

Sendo a variação e a mudança linguística o centro do interesse dos estudos em sociolinguística, os pesquisadores 
dessa área têm se dedicado a descrever os métodos utilizados em suas pesquisas, a fim de "captar o fenômeno da variação" (FREITAG, 2005, p.107). Labov (1994) questiona se, de fato, a variação e a mudança linguística podem mesmo ser observadas. Discute que a mudança linguística carrega, em sua premissa basilar, a doutrina do uniformitarismo, em oposição a um posicionamento teórico da catástrofe, que usa os fatos do presente para explicar o passado, por meio de processos em curso.

A proposta laboviana se apoia na argumentação de que se pode analisar a variação/mudança por meio da análise quantitativa das variantes em faixas etárias, ou análise em tempo aparente. A observação das variáveis usadas em dois ou mais períodos discretos denomina-se análise em tempo real. Esses dois princípios caracterizam o fundamento para a pesquisa sociolinguística e o seu interesse em definir se o uso de duas ou mais variantes encontra-se em variação estável ou se caracteriza uma mudança em curso.

\section{O CONSTRUTO DO TEMPO REAL E DO TEMPO APARENTE}

De acordo com Labov (2001), o estudo da variação, com base na noção de regra variável, remete a dois construtos de ordem teórico-metodológica: a variação em tempo real e tempo aparente. Estes tipos de pesquisas analisam 
a distribuição dos dados verificáveis com base nas faixas etárias dos participantes, com o interesse de "comprovar o convívio simultâneo dos diferentes estágios de mudança linguística numa comunidade" (BAGNO, 2017, p.455), quer sejam os estágios de estabilidade, mudança em estágio inicial, mudança progressiva ou mudança completa. No entanto, para que essas respostas sejam alcançadas, é necessário que seja realizado um estudo em tempo real.

Para o estudo da variação e mudança na perspectiva do tempo real, Labov (1994) propõe que o pesquisador colete dados de uma amostra e, passando-se um determinado período, contate-se os mesmos informantes, a fim de se repetir a coleta de dados, de modo que essa observação de um estado da língua seja feita por meio de uma análise quantitativa randomizada ${ }^{2}$ e, assim, sejam acessados todos os segmentos de uma comunidade de fala.

Os estudos de tempo real se organizam em estudos de tendência (trend study) ou estudos de painel (panel study). Os estudos de tendência se caracterizam pela organização de uma amostra da mesma comunidade algum tempo depois de coletada a primeira amostra. Os estudos de painel, mais complexos que os de tendência, são caracterizados

2 Entende-se por análise quantitativa randomizada o tipo de análise que se pauta na extração de dados sociolinguísticos a partir de uma amostra de fala estratificada aleatoriamente. Ressalta-se que, em geral, a aplicação dos pressupostos teórico-metodológicos variacionistas pelas diversas pesquisas realizadas nessa área, no Brasil, tem se pautado nesse modelo. 
pelo contato dos mesmos informantes da primeira coleta de dados e aplicação da mesma metodologia. As pesquisas de tempo real demandam tempo, independentemente de serem de painel ou de tendência, uma vez que necessitam de um espaço de tempo entre uma coleta e outra de dados.

De acordo com a Teoria da Variação e Mudança proposta por Labov ([1966]2006, 2001; [1972]2008), o princípio do uniformitarismo possibilita que o pesquisador interessado na mudança nos usos de determinadas formas apresente hipóteses acerca do processo de mudança na diacronia. Como se observou anteriormente, a principal característica desse princípio é o de que as mesmas forças responsáveis por operar mudanças no presente são da mesma natureza das forças que operaram no passado (LABOV, 1994; [1972]2008).

Baseado na hipótese clássica da aquisição da linguagem (que se encerraria) por volta dos quinze anos, o construto do tempo aparente postula que "o estado atual da língua de um falante adulto reflete o estado da língua adquirida quando - falante tinha aproximadamente quinze anos de idade" (NARO, 1992, p.82). Dessa forma, através de diferentes faixas etárias numa amostra de dados, é como se dispusesse de diferentes recortes no tempo - daí o termo "aparente".

Rocha (1997) atestou, em estudo comparativo entre o Rio de Janeiro e Brasília, que parece haver uma variação 
estável nas duas capitais, tendo em vista que, apesar de os mais jovens utilizarem mais o indicativo, não há uma diferença substancial com relação aos indivíduos mais velhos, que se correlacionam mais ao subjuntivo. Do mesmo modo, Carvalho (2007) verificou que há uma tendência de seleção do subjuntivo entre os sujeitos mais velhos no Ceará. Entretanto, diferentemente daquele estudo, este mostra um processo de mudança se iniciando nesse estado.

Assim, o interesse dessa variável está em verificar se, entre os mais jovens, é maior a tendência de emprego de formas do indicativo, em lugar de formas do subjuntivo, quando ambas são possíveis. Essa hipótese também foi prevista nas pesquisas de Pimpão (2012) e Santos (2015).

\section{METODOLOGIA}

Os estudos sociolinguísticos, em especial aqueles de cunho laboviano, têm interesse na mudança linguística, bem como em seus processos de encaixamento, avaliação e implementação (WEINREICH; LABOV; HERZOG, 1968). A partir de fatos de variação, interessa verificar se se trata de um fenômeno estável ou de um caso de mudança em progresso. Quando se trata de contextos em que formas verbais subjuntivas e indicativas se alternam - do modo como discute o capítulo anterior -, além de perguntar (i) a que se correlacionam os empregos de uma ou de outra 
forma?, uma questão que também se apresenta é: (ii) estaria uma das formas tornando-se preferida em alguns casos? Em outras palavras, considerando-se a discussão anteriormente desenvolvida: estaria o indicativo "tomando o lugar" do subjuntivo em certos contextos? Para analisar a variação nos usos do subjuntivo e do indicativo em Florianópolis, São Paulo e São Luís, utilizam-se, aqui, os dados coletados por Pimpão (2012) e Santos (2015).

Para a amostra florianopolitana, Pimpão (2012) utilizou entrevistas retiradas do Banco de Dados do Projeto VARSUL, cujo objetivo geral consiste em descrever o português falado e escrito de áreas socioculturalmente representativas de cada um dos estados da Região Sul do Brasil. "A estratificação sociolinguística aplicada à constituição do Banco VARSUL distribui os informantes em sexo, idade, escolaridade, região/etnia" (2012, p.177). Conforme mencionado, ela utilizou dados de 44 informantes (22 homens e 22 mulheres), organizados em três faixas etárias (15 a 24 anos, 25 a 50 anos e acima de 50 anos) e quatro níveis de escolaridade (primário, ginásio, colegial e universitários).

Para a análise comparativa entre São Paulo e São Luís, Santos (2015) utilizou 36 entrevistas (de um total de 60) realizadas com sujeitos nascidos e criados na capital paulista pelo Grupo de Estudos em Sociolinguística da USP (GESOL). 
Os informantes estão estratificados de acordo com o seu sexo/gênero, sua faixa etária e a escolaridade. Com base nessa estratificação, e a fim de manter a comparabilidade entre as amostras, o autor gravou mais 36 entrevistas com sujeitos ludovicenses, entre 2012 e 2013. A estratificação da amostra em Sexo/Gênero, Faixa Etária gera 12 perfis sociolinguísticos, com cada célula sendo composta por três informantes, totalizando, assim, 72 entrevistas sociolinguísticas.

Os dados de ambas as pesquisas foram analisados quantitativamente por meio de testes de natureza estatística de regressão logística através dos quais se verifica se as hipóteses se confirmam ou não - em outras palavras, se os grupos de fatores estabelecidos são ou não estatisticamente significativos para as ocorrências das formas variantes/alternantes. No presente trabalho, esses testes foram feitos com o pacote GoldVarb X (SANKOFF; TAGLIAMONTE; SMITH, 2005) que indica quais dos grupos de fatores são significativos fornece pesos relativos (índices que variam de zero a um, mas nunca se igualam a esses valores), que indicam tendências de ocorrências de uma ou de outra forma (aquele que se estabelece como valor de aplicação da análise estatística) diante dos fatores de cada grupo.

A seguir, apresentam-se os resultados alcançados por Pimpão (2012) e Santos (2015) para a variável faixa etária, de modo a estabelecer os padrões de usos nas três localidades estudadas. 


\section{ANÁLISE E DISCUSSÃO DOS RESULTADOS}

As análises objetivam verificar as diferenças na produção do modo subjuntivo e do indicativo por parte dos falantes florianopolitanos, paulistanos e ludovicenses, no que concerne à sua faixa etária, de modo que se possa observar os padrões de variação e/ou mudança nessas cidades.

\section{O USO VARIÁVEL DO PRESENTE DO SUBJUNTIVO EM FLORIANÓPOLIS}

Para a pesquisa realizada com dados de 44 informantes nascidos e residentes em Florianópolis, o controle de três faixas etárias tinha o objetivo de atestar a hipótese clássica nos estudos sociolinguísticos, segundo a qual a fala dos mais jovens tende a variar mais se comparada à fala dos mais velhos. Esse pressuposto está assentado na previsão de que a fala de um indivíduo se aproxima do seu padrão linguístico quando tinha 15 anos. Dessa forma, a título de ilustração, uma pessoa com 45 anos tende a representar sua fala de 30 anos atrás; assim como uma pessoa com 60 anos refletiria sua fala de 45 anos atrás. A expectativa de Pimpão (2012) acerca do condicionamento do grupo de fatores faixa etária sobre o uso variável do presente do subjuntivo, no entanto, não se confirmou, conforme pode ser observado na tabela a seguir. 


\begin{tabular}{c|c|c|}
\hline $\begin{array}{c}\text { Faixa } \\
\text { Etária }\end{array}$ & $\begin{array}{c}\text { Frequência/ } \\
\text { Total }\end{array}$ & $\%$ \\
\hline Acima de 50 anos & $117 / 195$ & 60 \\
\hline 25 a 50 anos & $88 / 150$ & 58 \\
\hline 15 a 24 anos & $55 / 100$ & 55 \\
\hline
\end{tabular}

Tabela 1 - Faixa etária e uso variável do presente do modo subjuntivo em Florianópolis. Adaptada de Pimpão (2012)

De acordo com os resultados apresentados na tabela 1, o percentual total de $58 \%$ para o uso do presente do modo subjuntivo não se mostra muito elevado, principalmente se comparado ao percentual para os dados de fala de informantes de São Luís - 70\% -, conforme será discutido adiante. O percentual de $58 \%$ aproxima-se do encontrado na amostra de fala de informantes de São Paulo - 61\%, abordada na subseção seguinte. Vale lembrar que, em Florianópolis, somente o presente do subjuntivo é investigado, ao passo que, para as outras duas capitais, são controlados os três tempos verbais desse mesmo modo (SANTOS, 2015).

Com relação à variável faixa etária, e de acordo com a tabela 1 , os resultados percentuais aumentam à medida que a faixa de idade avança em direção aos mais velhos. No entanto, conforme pode ser visualizado na tabela, a diferença percentual entre as faixas varia de $2 \%$ a $3 \%$; e, entre 
a primeira e a terceira, a diferença é de 5\%. Dessa forma, a despeito da distribuição gradual de presente do subjuntivo de acordo com a faixa etária, os resultados estão muito próximos. Provavelmente esse tenha sido um dos motivos pelos quais a variável em análise não obteve relevância estatística no estudo desenvolvido por Pimpão (2012). Não há indícios, portanto, de mudança em tempo aparente.

Diferentemente, a variável faixa etária obteve relevância estatística nas pesquisas de Rocha (1997), Carvalho (2007) e Alves (2009). Nos estudos desenvolvidos por Carvalho (2007), com dados de variação do presente do subjuntivo na fala de informantes da microrregião do Cariri/CE, e de Alves (2009), com dados do presente do subjuntivo na fala de informantes de Muriaé/MG, os mais velhos - acima de 50 anos e de 52 a 60 anos, respectivamente - preferem o uso da variante padrão. Um padrão curvilinear, em que os mais jovens preferem a forma inovadora e os mais velhos a variante conservadora, também foi encontrado na pesquisa realizada por Rocha (1997), que investiga o uso variável do presente e do imperfeito do subjuntivo na fala de informantes do Rio de Janeiro e de Brasília.

Visando aprofundar a discussão acerca da relevância da variável faixa etária, importa investigar a correlação entre essa variável e a denominada projeção temporal da situação 
codificada. Conforme previsão de Givón (1995; 2001), o subjuntivo é mais provável de ocorrer em contexto de projeção futura, pressuposto atestado por Pimpão (2012). Importante sob o ponto de vista teórico, a projeção temporal, controlada como variável, ainda obteve significância estatística em diferentes rodadas (PIMPÃO, 2012). Dessa forma, um cruzamento de variáveis pode reforçar os resultados da tabela 1, que apontam para uma variação sem indícios de mudança, ou pode revelar um possível estágio inicial de mudança.

Projeção Temporal

\begin{tabular}{|c|c|c|c|c|}
\hline & & $\begin{array}{c}\text { Com projeção } \\
\text { futura }\end{array}$ & $\begin{array}{l}\text { Sem projeção } \\
\text { futura }\end{array}$ & \\
\hline & & Freq./Total $\%$ & Freq./Total \% & \begin{tabular}{l|l} 
Total $\%$ & $\%$
\end{tabular} \\
\hline \multirow[t]{3}{*}{ Faixa Etária } & Acima de 50 anos & \begin{tabular}{l|l}
$37 / 42$ & 88
\end{tabular} & \begin{tabular}{l|l}
$80 / 153$ & 52
\end{tabular} & \begin{tabular}{|l|l|}
$117 / 195$ & 60
\end{tabular} \\
\hline & 25 a 50 anos & $35 / 50$ & ${ }_{53}$ & \begin{tabular}{|l|l|}
$88 / 150$ & 59
\end{tabular} \\
\hline & 15 a 24 anos & $11 / 17$ & 55 & \begin{tabular}{l|l}
$55 / 100$ & 55
\end{tabular} \\
\hline
\end{tabular}

Tabela 2 - Correlação entre faixa etária e projeção temporal da situação codificada e uso variável do presente do modo subjuntivo em Florianópolis. Adaptado de Pimpão (2012)

Conforme os resultados exibidos na tabela 2, os percentuais para os dados sem projeção futura situam-se próximo aos $50 \%$ independentemente da faixa etária, o que indica um comportamento estável do fenômeno variável em análise. Na ausência de projeção futura, o tempo presente não é 
preferido, seja no subjuntivo, seja no indicativo, resultado que aponta para uma neutralidade das formas variantes. Em contrapartida, o contexto com projeção futura constitui um ambiente preferencial ao uso do presente do subjuntivo na fala dos informantes com idade acima dos 50 anos, destacado pelo resultado de $88 \%$. Seja em termos teóricos (GIVÓN, 1995; 2001), seja em termos estatísticos, revela-se estreita a associação entre futuridade e subjuntivo. De acordo com os resultados apresentados, a projeção futura revela-se como um ambiente marcado, menos frequente e, por conseguinte, promove o uso da variante também marcada, o subjuntivo, menos frequente do que o indicativo, e mais complexo do ponto de vista do processamento, considerando que ocorre em determinados ambientes sintáticos.

Com uma diferença de 5 pontos percentuais entre a faixa etária intermediária (25 a 50 anos) e a faixa mais jovem (15 a 24 anos), o presente do subjuntivo se faz um pouco menos atuante em relação à faixa etária mais alta - 88\% -, ainda que o percentual não seja inexpressivo - 70\% e 65\% -, respectivamente. Na consideração desses percentuais, dois questionamentos emergem: (i) os jovens e os informantes pertencentes à faixa intermediária estariam dando início a um processo de mudança em direção a uma gradual substituição do presente do subjuntivo pelo presente do indicativo? 
Ou (ii) o que motivaria os indivíduos a usarem mais o subjuntivo ao atingirem a terceira faixa etária? A primeira situação caracterizaria uma mudança na comunidade e a segunda, uma mudança no indivíduo.

Antes de avançar na discussão desses questionamentos, é preciso considerar que as variáveis sociais não atuam, necessariamente, de maneira isolada. A faixa etária pode estar intimamente relacionada com a escolaridade. A depender da proposta de constituição de um determinado banco de dados e do perfil da comunidade investigada, pode ser que as células sociais não sejam ortogonais. É possível, nesse sentido, encontrar informantes sem nível universitário, como também não encontrar informantes analfabetos ou mesmo com o primeiro ciclo do Ensino Fundamental (in)completo, principalmente se a comunidade recebeu investimentos na educação. Assim posto, resultados para a faixa etária podem estar sendo atravessados pelo nível de escolaridade. Pensando nesse cotejo de variáveis, a tabela a seguir apresenta resultados para o cruzamento entre faixa etária e nível de escolaridade. 


\begin{tabular}{|c|c|c|c|c|}
\hline \multicolumn{5}{|c|}{ Faixa Etária } \\
\hline & & Acima de 50 anos & 25 a 50 anos & 15 a 24 anos \\
\hline & & Freq./Total \% & Freq./Total $\%$ & \begin{tabular}{l|l} 
Freq./Total & \%
\end{tabular} \\
\hline \multirow{4}{*}{ Escolaridade } & Primário & \begin{tabular}{l|l}
$10 / 21$ & 48
\end{tabular} & \begin{tabular}{l|l}
$22 / 44$ & 50
\end{tabular} & 53 \\
\hline & Ginasial & \begin{tabular}{l|l}
$34 / 61$ & 56
\end{tabular} & \begin{tabular}{l|l}
$13 / 32$ & 41
\end{tabular} & 47 \\
\hline & Colegial & \begin{tabular}{l|l}
$37 / 56$ & 66
\end{tabular} & $T_{57}$ & 60 \\
\hline & Universitário & \begin{tabular}{l|l}
$36 / 57$ & $\mathbf{6 3}$
\end{tabular} & 85 & 10 \\
\hline Total & & \begin{tabular}{l|l}
$117 / 195$ & 60
\end{tabular} & \begin{tabular}{l|l}
$88 / 150$ & 58
\end{tabular} & $55 / 100$ \\
\hline
\end{tabular}

Tabela 3 - Correlação entre faixa etária e nível de escolaridade e uso variável do presente do modo subjuntivo em Florianópolis. Adaptado de Pimpão (2012)

Um primeiro resultado a ser destacado na tabela 3 referese aos informantes com idade entre 15 e 24 anos e o nível universitário. Importa registrar que não há entrevistas que preencham essa célula social, o que significa afirmar que os informantes enquadrados nessa faixa etária estão entre o primário e o colegial. Nesse sentido, são oito entrevistas com universitários e doze para cada um dos demais níveis de escolaridade. A despeito disso, os percentuais gerais para cada faixa etária, identificados no total dos dados da tabela 3 e detalhados na análise da tabela 1, estão próximos. Fica a pergunta: se houvesse jovens com o nível universitário, o percentual seria mais elevado em relação aos universitários 
entre 25 e 50 anos? Ou o percentual se aproximaria? Esse resultado seria importante para verificar a atuação da variável escolaridade.

De qualquer forma, os universitários entre 25 e 50 anos elevam o percentual de uso de presente do modo subjuntivo e, em segundo lugar, os informantes com idade acima de 50 anos e nos níveis colegial e universitário. Esses resultados apontam mais na direção da escolaridade do que propriamente da faixa etária. Considerando a lacuna da célula social apontada no parágrafo anterior, não é possível assegurar tal afirmação, ficando, aqui, apenas uma hipótese acerca da relevância dos níveis mais altos de escolaridade para a compreensão dos resultados. A escolaridade ainda desponta na correlação com a variável projeção futura, conforme demonstra a tabela a seguir:

\begin{tabular}{|c|c|c|c|c|c|c|c|c|}
\hline \multicolumn{7}{c}{ Projeção Temporal } \\
\hline \multicolumn{7}{c}{$\begin{array}{c}\text { Com projeção } \\
\text { futura }\end{array}$} & $\begin{array}{c}\text { Sem projeção } \\
\text { futura }\end{array}$ & \\
\hline \\
\hline
\end{tabular}

Tabela 4 - Correlação entre nível de escolaridade e projeção temporal da situação codificada e uso variável do presente do modo subjuntivo em Florianópolis. Adaptado de Pimpão (2012) 
Os resultados apresentados na tabela 4 revelam os níveis mais elevados da escolaridade como aqueles que retêm o presente do subjuntivo, em especial nos três últimos correlacionados com a projeção futura. Mesmo com a ausência de projeção futura, os dois níveis de escolaridade mais elevados constituem ambiente propício ao presente do subjuntivo com valores superiores ao primário com projeção futura.

Em síntese, a escolaridade parece desempenhar alguma importância na retenção do presente do subjuntivo, ainda que os resultados precisem ser interpretados com cautela devido às células sociais não serem ortogonais, de acordo com o já mencionado. Soma-se a isso, o nítido estágio de variação estável, observado nos resultados apresentados na tabela 1. Resultados gerais para Florianópolis não indicam, portanto, estágios de mudança.

\section{O USO VARIÁVEL DO SUBJUNTIVO EM SÃO PAULO}

O pressuposto básico dos estudos sociolinguísticos é o de que as línguas são inerentemente heterogêneas e que tal heterogeneidade é regulada (e não caótica). Como já se verificou anteriormente, a pesquisa empreendida por Santos (2015) enfoca formas subjuntivas e indicativas que podem ocorrer em orações subordinadas adverbiais, substantivas 
e relativas. $\mathrm{O}$ autor propõe que as formas do subjuntivo e do indicativo funcionam como variantes nas orações adverbiais - já que, nelas, pode-se entender que as formas verbais constituem "modos diferentes de dizer a mesma coisa" (a definição laboviana de variantes de uma variável). Entretanto, ainda que nas outras duas estruturas de subordinação seja mais preciso falar em termos de alternância de formas, nos três contextos deve haver fatores que se correlacionam à ocorrência de formas do subjuntivo ou do indicativo.

\begin{tabular}{cccccc}
\hline $\begin{array}{c}\text { Orações } \\
\text { Subordinadas }\end{array}$ & Indicativo & $\%$ & Subjuntivo & $\%$ & Total \\
\hline Adverbiais & 172 & 29 & 414 & 71 & 586 \\
Substantivas & 96 & 53 & 85 & 47 & 181 \\
Relativas & 127 & 52 & 115 & 48 & 242 \\
\hline Total & 395 & 39,1 & 614 & 60,9 & 1009 \\
\hline
\end{tabular}

Tabela 5 - Distribuição geral dos dados - São Paulo. Adaptado de Santos (2015, p.81)

Com base nessa discussão proposta por Santos (2015), e na distribuição dos dados na amostra de fala analisada pelo autor, observa-se que, nos contextos em que as formas indicativas e subjuntivas podem co-ocorrer, a forma do subjuntivo parece ser preferida pelos falantes paulistanos. No geral, a tabela acima mostra que o indicativo não é mais frequente que o subjuntivo em todos os contextos (representando, aliás, "apenas" 29\% das ocorrências 
em orações adverbiais, contexto considerado pelo autor como aquele que ocorre variação de fato).

A análise quantitativa é feita da perspectiva do modo indicativo (ou seja, esta forma é estipulada como valor de aplicação nas análises estatísticas), já que o olhar aos dados se dá a partir da hipótese inicial de que o indicativo estaria se sobrepondo ao subjuntivo em certos casos; em outras palavras, pretende-se verificar se o uso do indicativo está aumentando em contextos nos quais o subjuntivo é forma possível ou "esperada".

Para o conjunto de dados de orações adverbiais não houve diferença estatística entre usar a morfologia do subjuntivo ou do indicativo e a faixa etária dos informantes paulistanos. A tabela 6 apresenta a distribuição dos dados para esse fator, bem como pesos relativos obtidos nas análises one-level.

\begin{tabular}{|c|c|c|c|c|}
\hline & & Indicativo/ & & Peso \\
\hline & Fatores & Total & $\%$ & Relativo \\
\hline \multirow[t]{3}{*}{ Faixa Etária } & $18-35$ & $70 / 239$ & 30 & [.49] \\
\hline & $36-59$ & $56 / 177$ & 31 & {$[.52]$} \\
\hline & $60 \mathrm{ou}+$ & $46 / 170$ & 27 & {$[.47]$} \\
\hline \multicolumn{5}{|l|}{ Total de } \\
\hline ocorrências & & $172 / 586$ & 30 & \\
\hline
\end{tabular}

Input:.293 Significância: 0.981

Tabela 6 - Orações adverbiais e Faixa Etária - São Paulo. Adaptado de Santos (2015, p.82). 
Os resultados para faixa etária revelam que, para as orações adverbiais, não há indício de mudança em curso em tempo aparente, com aumento gradativo de ocorrências do indicativo. Não há, tampouco, preferência estatisticamente significativa dessa forma por qualquer uma das faixas etárias. Observa-se, contudo, um favorecimento do indicativo entre os informantes da segunda faixa etária - normalmente mais sensível às pressões do "mercado linguístico" (BOURDIEU, 1991). Como este grupo de fatores não foi selecionado pela análise estatística, não convém interpretar tal resultado como um indício de que formas indicativas estariam gozando de algum prestígio encoberto na comunidade; entretanto, como se trata de um peso relativo que está acima do ponto neutro (diferentemente das duas outras faixas etárias), vale ter este como um resultado interessante, sobretudo em análises futuras, com dados de possíveis novas amostras que possam vir a ser coletadas.

Esse resultado, no conjunto, aponta para o fato de que, socialmente, não há diferenciação relevante entre os grupos de informantes mais idosos ou mais novos. No geral, os paulistanos empregam mais a forma do subjuntivo, nas orações subordinadas adverbiais.

Para o conjunto de orações subordinadas substantivas, ao contrário do que se observou para as orações subordinadas 
adverbiais, a variável faixa etária foi selecionada como estatisticamente significativa.

\begin{tabular}{|c|c|c|c|c|}
\hline & \multicolumn{3}{|c|}{ Indicativo/ } & \multirow{2}{*}{$\begin{array}{c}\text { Peso } \\
\text { Relativo }\end{array}$} \\
\hline & Fatores & Total & $\%$ & \\
\hline & $18-35$ & $47 / 66$ & 71 & .64 \\
\hline \multirow[t]{3}{*}{ Faixa Etária } & $36-59$ & $23 / 54$ & 42 & .36 \\
\hline & 60 ou + & $26 / 61$ & 42 & .46 \\
\hline & & & & Range: 28 \\
\hline Total & & $96 / 181$ & & \\
\hline
\end{tabular}

Input:.507 Significância: 0.032

Tabela 7: Orações substantivas e faixa etária - São Paulo

Adaptado de Santos (2015, p.87)

A tabela acima revela que, enquanto os mais jovens tendem a favorecer a forma do indicativo, os falantes da terceira faixa etária e os da faixa etária intermediária tendem a desfavorecê-la. Esses resultados, do modo como se dispõem, parecem indicar o início de uma mudança em curso em tempo aparente, em favor do indicativo orações subordinadas a verbos, mesmo que as tendências (pesos relativos) para os falantes da terceira faixa etária e os da faixa intermediária se assemelhem.

Para o conjunto de dados de orações subordinadas adjetivas, verificou-se que a faixa etária dos falantes também importa para a variação indicativo/subjuntivo. 


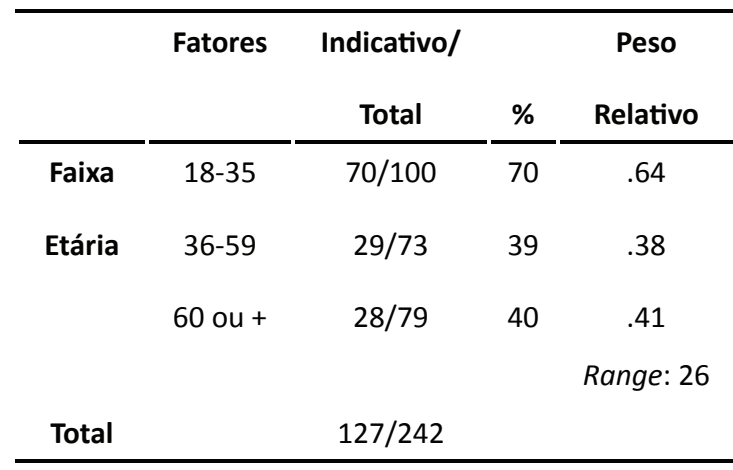

Input:0.525 Significância:0.01

Tabela 8: Orações adjetivas e faixa etária - São Paulo

Adaptado de Santos (2015, p.92)

Aqui, verifica-se fenômeno semelhante ao que se observou para as subordinadas substantivas: o indicativo é favorecido entre os mais jovens e desfavorecido entre os falantes da segunda e da terceira faixa etária. Considerandose que os falantes mais jovens tendem a ser mais sensíveis à sua rede de relações (Chambers, 2003), pensa-se que essa diferença entre as faixas se dê por conta dos posicionamentos estilísticos impostos aos indivíduos, em suas diferentes fases de vida. Enquanto os mais jovens estão mais livres das responsabilidades sociais (chefiar uma família, ou contribuir diretamente com a sua renda, por exemplo), os falantes mais adultos sofrem fortes pressões sociais, principalmente por conta do mercado de trabalho, o que leva à sua acomodação linguística. Assim, mais uma vez, temos um indício de mudança em curso, em tempo aparente, na direção do indicativo. 


\section{O USO VARIÁVEL DO SUBJUNTIVO EM SÃO LUÍS}

Com a intenção de comparar padrões, as mesmas análises anteriores foram desenvolvidas com dados extraídos das entrevistas com os sujeitos nascidos e criados na capital maranhense. A tabela a seguir apresenta a distribuição das ocorrências de indicativo e subjuntivo para cada um dos conjuntos de dados, na amostra ludovicense.

\begin{tabular}{cccccc}
\hline Orações & $\mathbf{N}$ & \multicolumn{1}{c}{$\mathbf{N}$} \\
Subordinadas & Indicativo & $\%$ & Subjuntivo & $\%$ & Total \\
\hline Adverbiais & 84 & 22,3 & 293 & 77,7 & 377 \\
Substantivas & 63 & 33,5 & 125 & 66,5 & 188 \\
Relativas & 99 & 39 & 155 & 61 & 254 \\
\hline Total & 246 & 30,1 & 573 & 69,9 & 819 \\
\hline
\end{tabular}

Tabela 9 - Distribuição geral dos dados - São Luís Adaptado de Santos (2015, p.94)

Para as orações adverbiais, as análises mostram que o grupo de fatores faixa etária não é estatisticamente significativo - assim como ocorreu para o mesmo conjunto de dados na amostra paulistana. A tabela a seguir apresenta pesos relativos obtidos de uma análise one-level. 


\begin{tabular}{ccccc}
\hline & Fatores & \multicolumn{1}{c}{ Indicativo/ } & & Peso \\
& & Total & $\%$ & Relativo \\
\cline { 3 - 5 } Faixa & $18-35$ & $46 / 149$ & 30 & {$[.61]$} \\
Etária & $36-59$ & $21 / 121$ & 17 & {$[.43]$} \\
& 60 ou + & $17 / 107$ & 15 & {$[.40]$} \\
Total & & $84 / 377$ & & \\
\hline
\end{tabular}

Input: 0.292 Significância: 0,001
Tabela 10 - Orações adverbiais e faixa etária - São Luís
Adaptado de Santos (2015, p.95)

De forma semelhante ao que se verificou para a amostra paulistana, apesar de faixa etária não ter sido um grupo selecionado, há uma diferenciação entre mais jovens e as outras duas faixas. Assim, também da mesma forma como se procedeu anteriormente, a segunda e a terceira faixa foram amalgamadas e realizou-se uma nova análise dos dados. Aqui, diferentemente do que se observou para os dados paulistanos, tal amalgamação levou à seleção deste grupo como significativo.

\begin{tabular}{|c|c|c|c|c|}
\hline & Fatores & Indicativo/ & & Peso \\
\hline & & Total & $\%$ & Relativo \\
\hline Faixa & $18-35$ & $46 / 149$ & 30 & .59 \\
\hline \multirow[t]{2}{*}{ Etária } & $36-59 / 60$ ou + & $38 / 228$ & 16 & .44 \\
\hline & & & & Range: 15 \\
\hline Total & & $84 / 377$ & & \\
\hline
\end{tabular}


Observa-se, desse modo, que é significativa a diferença entre os mais jovens, de um lado, e os falantes que têm 36 anos ou mais. Este é um padrão um tanto diferente daquele que se depreendeu da análise dos dados paulistanos, cuja amalgamação das duas faixas etárias mais velhas não resultou na seleção do grupo como significativo. Aqui, portanto, temos que, mesmo nas subordinadas adverbiais, há uma tendência de aumento do emprego do indicativo entre os mais jovens.

Tal resultado contraria, portanto, as expectativas iniciais pelo menos no que concerne a subordinadas adverbiais - de que ludovicenses usam mais subjuntivo do que paulistanos. Conforme se mostrou na Tabela 6 , os pesos para as três faixas etárias nos dados paulistanos estavam muito mais próximos entre si (de modo que a amalgamação da segunda e da terceira não levou à seleção do grupo). Em outras palavras, temos indício de mudança nos usos ludovicenses em direção ao indicativo - mas não nos paulistanos.

\begin{tabular}{|c|c|c|c|c|}
\hline & Fatores & $\begin{array}{c}\text { Indicativo/ } \\
\text { Total }\end{array}$ & $\%$ & $\begin{array}{c}\text { Peso } \\
\text { Relativo }\end{array}$ \\
\hline Faixa & $18-35$ & $32 / 71$ & 45 & .63 \\
\hline \multirow[t]{3}{*}{ Etária } & $36-59$ & $18 / 59$ & 30 & .45 \\
\hline & $/ 60$ ou + & $13 / 58$ & 22 & .38 \\
\hline & & & & Range: 25 \\
\hline Total & & $63 / 188$ & & \\
\hline
\end{tabular}

Input: 0.170 Significância: 0.038

Tabela 12 - Orações substantivas e faixa etária - São Luís

Adaptado de Santos (2015, p.100) 
Tal processo parece se confirmar também quando os contextos analisados são os de orações subordinadas substantivas. Entre as três variantes dessa variável (Tabela 12, acima), são os sujeitos da primeira faixa os que mais favorecem a forma inovadora, com peso relativo .63, seguidos dos sujeitos da segunda faixa, com peso .45, e encerrando com os indivíduos mais idosos, com peso .38. Com esses pesos relativos, e range 25 , parece haver a indicação de um processo de mudança se iniciando na variedade do português ludovicense.

Observe-se que, para a variedade paulistana, esse grupo de fatores também foi selecionado, com o acréscimo da informação de que o processo de mudança parece estar mais difundido na variedade paulistana (71\%), e uma diferença de mais ou menos 30\% com relação aos indivíduos de segunda e terceira faixas etárias, enquanto que em São Luís, a diferença entre os mais jovens, que apresentam uma frequência de $45 \%$ de seleção da forma mais inovadora, e os sujeitos mais adultos gira em torno de $20 \%$.

Para o conjunto de dados de orações relativas, Santos (2015) observou que "somente" a faixa etária dos falantes, dentre os fatores sociais analisado, foi considerado como estatisticamente significativo pelo GoldVarb X. 


\begin{tabular}{|c|c|c|c|c|}
\hline & Fatores & $\begin{array}{c}\text { Indicativo/ } \\
\text { Total }\end{array}$ & $\%$ & $\begin{array}{c}\text { Peso } \\
\text { Relativo }\end{array}$ \\
\hline Faixa & $18-35$ & $28 / 79$ & 35 & .43 \\
\hline \multirow[t]{2}{*}{ Etária } & $36-59$ & $46 / 84$ & 54 & .63 \\
\hline & $/ 60$ ou + & $28 / 81$ & 34 & $\begin{array}{c}.42 \\
\text { Range: } 25\end{array}$ \\
\hline Total & & $63 / 188$ & & \\
\hline
\end{tabular}

Input: 0.321 Significância: 0.028

Tabela 13 - Orações adjetivas e faixa etária - São Luís

Adaptado de Santos (2015, p.105)

O padrão que se observa para a variedade ludovicense é a de que, no que concerne às orações subordinadas adjetivas, não há movimento que indique mudança, ao contrário do resultado a que o autor alcançou para as subordinadas substantivas, por exemplo, para as quais o aumento na tendência de emprego do indicativo é praticamente linear. Com esse resultado para as orações adjetivas, Santos (2015) explica que é difícil interpretar o fato de que os informantes da segunda faixa etária favoreçam o indicativo (em orações relativas) relativamente aos mais velhos e aos mais novos, já que, supondo-se que formas subjuntivas são prescritas em alguns casos, seria de esperar que o indicativo fosse evitado por estes falantes que, de acordo com a noção de "mercado linguístico" (BOURDIEU, 1991), sofreriam maior pressão social no sentido de empregar formas "mais adequadas e prestigiadas". 
De qualquer modo, ainda de acordo com o autor, o aspecto mais interessante a ser destacado é o de que, em São Luís, as tendências de uso são bastante diferentes quando se trata de orações substantivas e de orações relativas - mudança na direção do indicativo no primeiro, estabilidade no segundo.

\section{A busca por um padrão}

Com base nos resultados explicitados acima, pode-se depreender que o fenômeno de variação entre as formas do subjuntivo e do indicativo são bastante complexas. Embora se tenha dados de "apenas" três localidades, este trabalho sinaliza a complexidade que envolve a busca por um padrão nos usos dessas formas verbais.

Entre os florianopolitanos, Pimpão (2012) observou que a variação entre o subjuntivo e o indicativo passa por um processo de variação estável. Santos (2015), por sua vez, concluiu que o uso do subjuntivo e do indicativo entre paulistanos e ludovicenses, a faixa etária indica processos de variação mais avançados na capital paulista, mas observa um processo de mudança se iniciando na capital maranhense. 


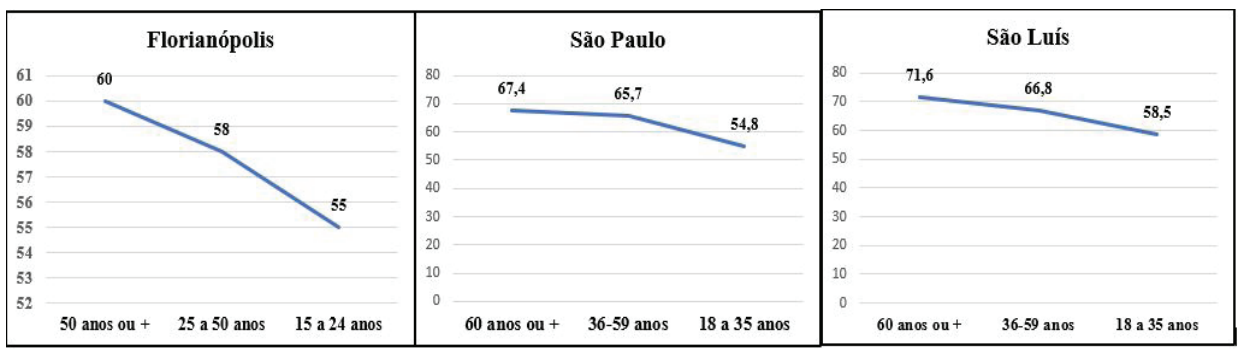

Imagem 1: Distribuição das ocorrências de subjuntivo em Florianópolis, São Paulo e São Luís. Fonte: Elaborado pelos autores.

De um modo geral, o que se observa, de acordo com a imagem 1, acima, é que os mais jovens tendem a usar menos o subjuntivo do que os falantes da faixa etária intermediária e os falantes mais idosos. Enquanto em Florianópolis a diferença de usos do subjuntivo entre os falantes mais idosos parece ser maior (60\%), São Paulo e São Luís tendem a se aproximar quanto ao uso desse modo verbal. Acrescentase a informação de que, para cada cidade, o movimento de variação e mudança é bastante particular para as localidades investigadas.

\section{CONSIDERAÇÕES FINAIS}

Este estudo focalizou a alternância de formas indicativas e subjuntivas em contextos nos quais ambas são possíveis: orações subordinadas adverbiais (é como se pra gente era) fosse normal), substantivas (eu sempre achava que ele ia/fosse dar bronca na gente) e relativas (não tem gente que anda/ 
ande de Porsche na Freguesia do Ó). Mais especificamente, discutiu o construto do tempo aparente a partir da apresentação dos resultados de análises multivariadas para o grupo de fatores faixa etária, com dados de falantes de Florianópolis, São Paulo e São Luís.

Os resultados apontaram para o fato de que Florianópolis passa por um processo de variação estável (PIMPÃO, 2012), São Paulo apresenta um estágio de mudança mais avançado que a capital catarinense e São Luís, que apresenta um processo de mudança se iniciando (SANTOS, 2015). Nesse sentido, o trabalho mostra que padrões de encaixamento linguístico e social de formas alternantes são bastante mais complexos do que se pode pensar: certamente, a realidade dos dados não confirma visões de "distribuição complementar", do tipo: tais falantes usam tais formas; outros falantes usam outras formas.

Com a análise comparativa de dados coletados em três comunidades urbanas tão distintas, espera-se ter contribuído para o desenho de um mapa dos padrões de uso de formas subjuntivas e de sua progressiva substituição por formas indicativas, sobretudo em virtude dos padrões depreendidos em tempo aparente. 


\section{REFERÊNCIAS}

ALMEIDA, Erica de Sousa (2010). Variação de uso do subjuntivo em estruturas subordinadas: do século XIII ao XX. 2010. 294f. (Tese Doutorado em Letras Vernáculas) - Programa de Pós-graduação em Letras Vernáculas, Universidade Federal do Rio de Janeiro, Rio de Janeiro. ALVES, Rosana (2009). A expressão de modalidades típicas do subjuntivo em duas sincronias do português: século XVI e contemporaneidade. $197 f$. (Tese - Doutorado em Linguística) - Instituto de Estudos da Linguagem, Universidade Estadual de Campinas, Campinas.

ALVES NETA, Ana (2000). O uso de formas do indicativo por formas do subjuntivo no português brasileiro. 114f. (Dissertação - Mestrado em Letras: Linguística) - Faculdade de Letras, Universidade Federal de Minas Gerais, Belo Horizonte.

BAGNO, Marcos (2017). Dicionário Crítico de Sociolinguística. São Paulo: Parábola Editora.

BARBOSA, Astrid Franco (2011). Alternância de formas indicativas e subjuntivas na fala de Vitória (ES). 2011. 146f. Dissertação (Mestrado em Linguística) - Universidade Federal do Espírito Santo, Vitória.

BECHARA, Evanildo (2006). Moderna gramática portuguesa. 37.ed. (revista e ampliada). Rio de Janeiro: Lucerna.

BOURDIE, Pierre (1991). Language and Simbolic Power. Cambridge: Polit Press.

BOTELHO PEREIRA, Maria Ângela (1974). Aspectos da oposição modal indicativo/subjuntivo no Português Contemporâneo. Rio de Janeiro: UFRJ, 1974 (Dissertação - Mestrado em Linguística), Curso de Pós-Graduação em Linguística, Universidade Federal do Rio de Janeiro.

CARVALHO, Hebe Macedo de (2007). A alternância indicativo/subjuntivo nas orações substantivas em função dos tempos verbais presente e imperfeito na língua falada do Cariri. 158f. Tese (Doutorado em Linguística) - Departamento de Letras Vernáculas, Universidade Federal do Ceará, Fortaleza. 
CHAMBERS, J. (2003). Sociolinguistics. 2.ed. Oxford: Blackwell. COSTA, lara Bemquerer (1990). O verbo na fala de camponeses: um estudo de variação. 223f. (Tese - Doutorado em Linguística) - Instituto de Estudos da Linguagem, Universidade Estadual de Campinas, Campinas.

CUNHA, Celso; CINTRA, Luís Felipe Lindley (1985). Nova Gramática do português contemporâneo. Rio de Janeiro: Nova Fronteira.

FAGUNDES, Edson Domingos (2007). As ocorrências do modo subjuntivo nas entrevistas do VARSUL no estado do Paraná e as possibilidades de variação com o modo indicativo. 2007. 189f. (Tese - Doutorado em Letras), Universidade Federal do Paraná, Curitiba.

FREIRE, Ricardo (2006). "Subjuntivo à paulista". Revista Época, São Paulo: Globo, edição 400 de 16 jan., ano 8. São Paulo, p.98.

FREITAG, Raquel Meister Ko (2005). “Idade: uma variável sociolingüística complexa". Línguas \& Letras, 6(11), p.105-121.

GIVÓN, Talmy (1995). Functionalism and grammar. Amsterdam/ Philadelphia: John Benjamins.

(2001). Syntax: an introduction. Amsterdam/Philadelphia: John Benjamins, vols. I e II.

GUY, Gregory; ZILLES, Ana (2007). Sociolinguística quantitativa: instrumental de análise. São Paulo: Parábola Editorial.

HONÓRIO DO COUTO, Hildo (1986). O Que é Português Brasileiro. São Paulo: Brasiliense.

LABOV, William ([1972]2008). Padrões sociolinguísticos. Marcos Bagno, Maria Marta Pereira Scherre, Caroline Rodrigues Cardoso (Trad.). São Paulo: Parábola Editorial.

(1994). Principles of linguistic change. Volume I: internal factors. Oxford: Blackwell.

(2001). Principles of linguistic change: social factors. Oxford: Blackwell.

(2006[1966]). The social stratification of English in New York City. São Paulo: Cambridge University Press. 
(1978). "Where does the sociolinguistic variable stop? A response to Beatriz Lavandera". In Working Papers in Sociolinguistics.

LAVANDERA, Beatriz (1978). "Where does the sociolinguistic variable stop?" Language in Society 7, 171-182.

MEIRA, Vivian (2006). O uso do modo subjuntivo em orações relativas e completivas no português afro-brasileiro. 2006. 317f. Dissertação (Mestrado em Letras e Linguística) Universidade Federal da Bahia, Salvador.

MENDES DE ALMEIDA, Napoleão (2005). Gramática metódica da língua portuguesa. 45.ed. São Paulo: Saraiva.

NARO, Anthony. Julius (1992). "Modelos quantitativos e tratamento estatístico". In: MOLLICA, M. (Org.). Cadernos didáticos UFRJ: Introdução à sociolinguística variacionista. Rio de Janeiro: UFRJ, p.17-25.

PERINI, Mário (2010). Gramática Descritiva do Português. São Paulo: Parábola.

PIMPÃO, Tatiana Schwochow (1999). Variação no presente do indicativo do modo subjuntivo: uma abordagem discursivo-pragmática. Florianópolis, 1999. 128f. (Dissertação - Mestrado em Linguística) - Universidade Federal de Santa Catarina.

(2012). Uso variável do presente no modo subjuntivo: uma análise de amostras de fala e escrita das cidades de Florianópolis e Lages nos séculos XIX e XX. Florianópolis. 350f. (Tese - Doutorado em Linguística) Universidade Federal de Santa Catarina.

ROCHA, Rosa Cecília da (1997). A alternância indicativo/subjuntivo nas orações subordinadas substantivas em português. 123f. (Dissertação de Mestrado em Linguística), Universidade de Brasília, Brasília.

SANKOFF, David; TAGLIAMONTE, Sali; SMITH, Eric (2005). Goldvarb X: A variable rule application for Macintosh and Windows. Department of Linguistics, University of Toronto.

SANTOS, Regina Alves dos (2005). O uso variável do modo subjuntivo em estruturas complexas. 2005. 170f. (Dissertação de Mestrado em Estudos Linguísticos), Universidade Estadual Paulista, São José do Rio Preto. 
SANTOS, Wendel Silva dos (2015). A morfologia do indicativo na expressão do modo subjuntivo em São Paulo e São Luís. 140f. (Dissertação de Mestrado em Semiótica e Linguística Geral), Universidade de São Paulo, São Paulo.

TRAVAGLIA, Luis Carlos (1996). Gramática e Interação: uma proposta para o ensino de gramática no 10 e 2o graus. São Paulo: Cortez.

WEINREICH, Uriel; LABOV, William e HERZOG, Marvin ([1968]2006). Fundamentos empíricos para uma teoria da mudança linguística. São Paulo: Parábola.

WHERRITT, Irene M. The subjunctive in Brazilian Portuguese (1977). $191 \mathrm{f}$. (Tese - Doutorado em Filosofia), University of New Mexico, Albuquerque.

Tatiana Schwochow Pimpão possui Doutorado em Linguística (2012) e Mestrado em Linguística (1999), ambos pela Universidade Federal de Santa Catarina. É professora na Universidade Federal do Rio Grande (FURG), atuando na Graduação em Letras e no Curso de Pós-Graduação Lato Sensu em Linguística e Ensino de Língua Portuguesa.

Wendel Silva dos Santos é Graduado em Letras pela Universidade Federal do Maranhão (UFMA). Mestre em Linguística pela Universidade de São Paulo (USP). Atualmente é professor Assistente do curso de Letras da Universidade Federal do Maranhão, e desenvolve pesquisa de doutorado em Linguística na Universidade de São Paulo. É membro do Grupo de Estudos e Pesquisa em Sociolinguística (GESOL-USP). Tem experiência na área de Linguística, com ênfase em Sociolinguística Variacionista, atuando nos seguintes temas: português brasileiro; variação morfossintática, variação e mudança linguística, percepção sociolinguística 